\title{
Hearing Assessment in Infants with Otoacoustic Emission and Auditory Brainstem Response: A Retrospective Study
}

\author{
Reshma P Chavan ${ }^{1}$, Shivraj M Ingole ${ }^{2}$, Ajay P Damodhar ${ }^{3}$, Gajanan S Kanchewad ${ }^{4}$
}

\begin{abstract}
Aim and objective: An attempt was made to find hearing status in all high-risk infants and no risk infants with the help of otoacoustic emission $(\mathrm{OAE})$ and auditory brainstem response (ABR).

Materials and methods: A retrospective study of hearing assessments of 330 infants was done with OAE and ABR from August 2019 to February 2020 at tertiary hospital. Various details of all participants such as age, sex, high-risk factors, detailed history of the current disease, maternal history during pregnancy, and complications during delivery were recorded.

Results: Among 330 infants, 156 (47.27\%) had REFER on first OAE. All 30 infants who had REFER on second OAE had shown hearing impairment on ABR. Hearing loss was seen in three infants $(0.90 \%)$ without any risk factor. In the present study, risk factors for the hearing impaired infants were NICU stay (39\%), low birth weight (33.6\%), LSCS (20.6\%), preterm delivery (17\%), hyperbilirubinemia (8.1\%), and delayed cry (7.57\%). Statistical analysis performed using the Chi-square test had shown significant association between NICU stay, low birth weight, delayed cry, and hearing loss.
\end{abstract}

Conclusion: Statistical analysis performed using the Chi-square test had shown significant association between NICU stay, low birth weight, delayed cry, and hearing loss.

Clinical significance: OAE is good screening tool for newborn and infants.

Keywords: Brainstem-evoked response audiometry, Hearing assessment, Hearing loss, High-risk infants, Newborn, Otoacoustic emission.

Otorhinolaryngology Clinics: An International Journal (2021): 10.5005/jp-journals-10003-1382

\section{INTRODUCTION}

Hearing loss is the most common congenital factor seen in $0.1-0.2 \%$ infants. ${ }^{1}$ The use of hearing aid and early rehabilitation is needed for development of speech. Auditory stimulation is needed in early months of life for preservation of neural connections in auditory pathways. ${ }^{2}$ Hearing aid and rehabilitation treatment within early months of life, speech and language development, psychological support, and school and social attachments are needed for better development. ${ }^{3}$ Infants hearing screening programs are helpful to find all cases with mild-severe hearing loss (>35-40 dB HL). ${ }^{4}$ According to $\mathrm{WHO}, 360$ million people have moderate to profound hearing loss worldwide, which makes them disable. ${ }^{5}$ In infants with normal hearing and good cochlear function, outer hair cells give nonlinear responses to sound stimulus. 5 , Populations with more chances of hearing impairment should be screened first in neonatal screening. ${ }^{7}$ Joint Committee on Infant Hearing $(\mathrm{JClH})$ had given risk factors to identify high-risk infants. ${ }^{8}$ No risk factor was seen in $50 \%$ of the infants with hearing loss. ${ }^{9}$ Screening of all infants is needed to avoid missed cases. ${ }^{10}$ Hearing assessment with otoacoustic emission (OAE) will not be helpful in the cases of auditory neuropathy, other neural problems, fluid in the middle ear, and vernix in the eternal auditory canal at birth. All infants should be screened with OAE and auditory brainstem response (ABR) to get more hearing-impaired cases. ${ }^{11}$ $\mathrm{OAE}$ and automated $\mathrm{ABR}$ ( $\mathrm{AABR}$ ) are hearing screening methods. Both OAE and AABR are nonsubjective, cost-effective, safe, and noninvasive. ${ }^{12}$ OAE is less time and money saving test as it does not require the use of the electrode. Otoacoustic emission test can be done in OPD in awake infants and $A B R$ requires the infant sleep. No complications report from OAE testing. "PASS" results
1,3,4 Department of ENT, Government Medical College, Miraj, Maharashtra, India

${ }^{2}$ Department of Radiology, Grant Government Medical College and Sir JJ Group of Hospitals, Solapur, Maharashtra, India

Corresponding Author: Reshma P Chavan, Department of ENT, Government Medical College, Miraj, Maharashtra, India, e-mail: entproblem@gmail.com

How to cite this article: Chavan RP, Ingole SM, Damodhar AP, et al. Hearing Assessment in Infants with Otoacoustic Emission and Auditory Brainstem Response: A Retrospective Study. Int J Otorhinolaryngol Clin 2021;13(2):29-33.

Source of support: Nil

Conflict of interest: None

show no hearing loss. "REFER" results need further assessment. $A B R$ tests require more time and are expensive. $A B R s$ are more sensitive than OAEs. As an ABR is a reliable and objective test but difficult to perform, otoacoustic emission is a practicable screening modality.

\section{Materials and Methods}

A retrospective study of all infants referred for hearing assessment with the help of OAE and ABR was carried out from August 2019 to February 2020 at Government Medical College, Miraj, Maharashtra. All infants referred to the ENT department for hearing assessment were included in the present study. Written informed consent of a parent was taken before the procedure. OAE was done on infants two times during the first 3 months age of infants. If OAE comes as

(c) The Author(s). 2021 Open Access This article is distributed under the terms of the Creative Commons Attribution 4.0 International License (https://creativecommons. org/licenses/by-nc/4.0/), which permits unrestricted use, distribution, and non-commercial reproduction in any medium, provided you give appropriate credit to the original author(s) and the source, provide a link to the Creative Commons license, and indicate if changes were made. The Creative Commons Public Domain Dedication waiver (http://creativecommons.org/publicdomain/zero/1.0/) applies to the data made available in this article, unless otherwise stated. 
"REFER" twice, then we are done auditory brainstem response for infants older than 3 months.

Infants included in this study were from OAE and BERA Record Book. OAE was done by using the NEUROSOFT diagnostic OAE machine. A probe was inserted into both external auditory canals of an infant alternately to measure inner ear responses to sound signals given by a probe which was inserted into the external auditory canal. Responses of outer hair cells were recorded. OAE results were noted as either PASS or REFER. An infant with bilateral ear PASS result suggests normal outer hair cell function. These infants were not advised to follow up. Follow-up after a few weeks for repeat OAE was advised to the infants with unilateral or bilateral REFER results. After two consecutive unilateral or bilateral "REFER" OAEs, infants referred for ABR testing. The ABR was done by NEUROSOFT BERA machine. ABR results were based on the morphology of wave five. Data were collected in a case sheet from departmental AABR records. Statistical analysis was performed using the Chi-square test.

\section{Results}

Among 330 infants, 188 were males and 142 were females (Fig. 1). About 109 males and 87 females screened with first OAE had bilateral PASS result. About 79 male infants and 55 female infants given REFER result on first OAE were called for second OAE. Totally 174 infants had bilateral PASS results on first OAE. One hundred and thirty four infants had bilateral REFER, 15 infants had right PASS and left REFER while seven infants had left PASS and right REFER on first OAE. All 156 infants with REFER result were called for second $O A E$. On second $O A E, 30$ infants had REFER result. All REFER 30 infants were called for ABR after second OAE. No infant had lost follow-up for ABR. Distribution of hearing impaired according to risk factors is shown in Figure 2. Among 20 infants without any risk factor, three infants were having REFER, and 17 had PASS results on OAE. Statistical analysis was done with a Chi-square test to find an association between hearing loss and factors studied.

All 30 infants had provided strong behind the ear hearing aid through Rashtriya Bal Swasthya Karyakram. Infants were given speech therapy and advised to continue speech therapy sessions. Parents were convinced for cochlear implant under Rashtriya Bal Swasthya Karyakram.

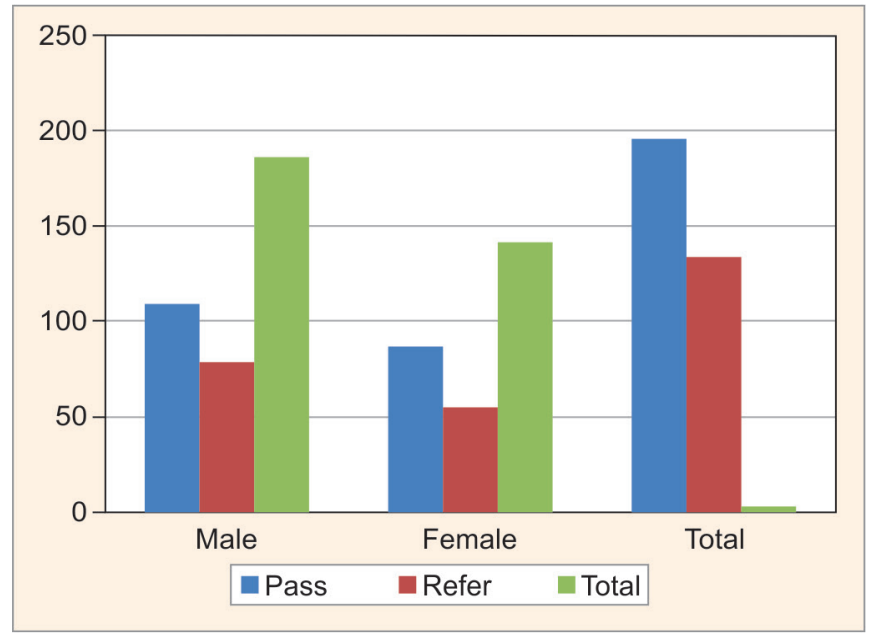

Fig. 1: Male and female distribution of OAE results (PASS and REFER)

\section{OAE Screening According to Craniofacial Malformation and Family History}

In the present study, no infant had craniofacial abnormalities. Three infants had a family history of deafness. Among three infants with family history of deafness, two had bilateral PASS and one infant had REFER result on OAE. No infant had given a history of TORCH infection.

One hundred and seventy eight infants who immediately cried after birth had PASS OAE results, and 109 infants had REFER OAE results. Eighteen infants who had delayed cry after birth had PASS OAE results, and 25 infants had REFER OAE results. After applying the Chi-square test, $p<0.05$. There is a significant association between hearing loss and cry after birth (Table 1). Infants who had delayed birth cry had more chances of hearing loss.

One hundred and twenty-nine infants delivered after 9 months of pregnancy had PASS OAE results, and 78 had REFER OAE results. Sixty-seven infants delivered before the completion of 9 months of gestational age (prematurity) had PASS results, and 56 had REFER $\mathrm{OAE}$ results. After applying the Chi-square test, $p>0.05$, so there is no significant association between hearing loss and gestational age of infants (Table 2).

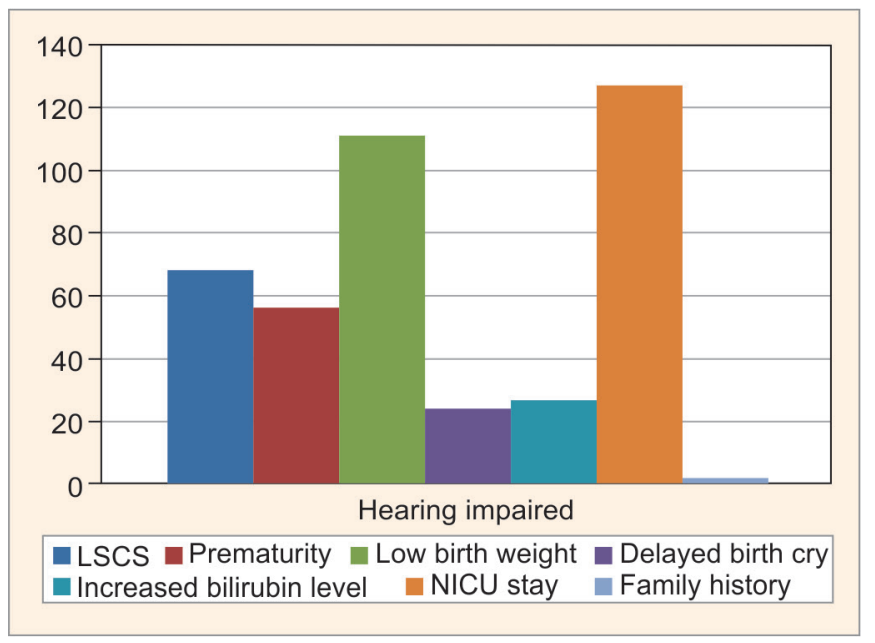

Fig. 2: Distribution of hearing impaired according to risk factors

Table 1: Distortion product otoacoustic emissions (DPOAEs) screening according to birth cry

\begin{tabular}{lcc}
\hline Cry after birth & PASS & REFER \\
\hline Immediate & 178 & 109 \\
Delayed & 18 & 25 \\
Chi-square test value & 6.3024 & \\
$p$ value & $0.012058<0.05$ & \\
Association & Significant & \\
\hline
\end{tabular}

Table 2: DPOAE screening according to gestational age (full term of preterm)

\begin{tabular}{lcc}
\hline Birth weight & PASS & REFER \\
\hline Full term & 129 & 78 \\
Preterm & 67 & 56 \\
Chi-square test value & 1.97 & \\
$p$ value & $0.160447>0.05$ & \\
Association & Not significant & \\
\hline
\end{tabular}


About 172 infants who had a history of NICU stay had PASS OAE results, and 127 infants had REFER OAE results. Twenty-four infants with no history of NICU stay had PASS OAE results, and seven infants had REFER OAE results. After applying the Chi-square test, $p<0.05$, so there is a significant association between hearing loss and NICU stay (Table 3). NICU infants had more chances of hearing loss.

About 102 infants with low birth weight $(<2.5 \mathrm{~kg})$ had PASS OAE results, and 111 infants with low birth weight $(<2.5 \mathrm{~kg})$ had REFER OAE results. Twenty-three infants with normal birth weight had REFER OAE results. After applying the Chi-square test, $p<0.05$, so there is a significant association between hearing loss and birth weight (Table 4). Infants with low birth weight had more chances of hearing loss.

About 175 infants who had a normal bilirubin level had PASS OAE results, and 107 infants had REFER OAE results. Twenty-one infants with increased bilirubin levels had PASS OAE results, and twenty-seven infants had REFER OAE results. After applying the Chi-square test, $p<0.05$, so there is a significant association between hearing loss and hyperbilirubinemia (Table 5). Infants with increased bilirubin level had more chances of hearing loss.

About 113 infants delivered naturally without surgical intervention had PASS OAE results, and 66 had REFER OAE results. Eighty-three infants delivered by caesarian section had PASS result, and sixty-eight had REFER OAE results. After applying the Chi-square

Table 3: DPOAE screening according to NICU stay

\begin{tabular}{lcc}
\hline DPOAE & PASS & REFER \\
\hline NICU stay & 172 & 127 \\
No NICU stay & 24 & 07 \\
Chi-square test value & 6.3024 & \\
$p$ value & $0.012058<0.05$ & \\
Association & Significant & \\
\hline
\end{tabular}

Table 4: DPOAE screening according to birth weight

\begin{tabular}{lcc}
\hline Birth weight & PASS & REFER \\
\hline Birth weight $<2.5 \mathrm{~kg}$ & 102 & 111 \\
Birth weight $>2.5 \mathrm{~kg}$ & 94 & 23 \\
Chi-square test value & 32.9815 & \\
$p$ value & $<0.00001$ & \\
Association & Significant & \\
\hline
\end{tabular}

Table 5: DPOAE screening according to hyperbilirubinemia

\begin{tabular}{lcc}
\hline Bilirubin level & PASS & REFER \\
\hline Normal & 175 & 107 \\
Hyperbilirubinemia & 21 & 27 \\
Chi-square test value & 6.3024 & \\
$p$ value & $0.012058<0.05$ & \\
Association & Significant & \\
\hline
\end{tabular}

Table 6: DPOAE screening according to mode of delivery

\begin{tabular}{lcc}
\hline OAE & PASS & REFER \\
\hline Normal & 113 & 66 \\
Caesarian section & 83 & 68 \\
Chi-square test value & 2.2622 & \\
$p$ value & 0.136425 & \\
Association & Not significant & \\
\hline
\end{tabular}

test, $p>0.05$, so there is no significant association between hearing loss and mode of delivery (Table 6).

All 30 infants had given strong power behind the ear hearing aid through rashtriya bal swasthya karyakram (RBSK). Speech therapy was started in 20 patients, and parents were convinced for cochlear implant surgery under rashtriya bal suraksha karyakram (RBSK).

\section{Discussion}

In the literature, permanent hearing loss is seen in 4(1.1-6) per $1000 .^{13}$ Early detection of hearing loss is necessary for the rehabilitation of such infants. Risk indicators for hearing loss in infants had given by Joint Committee on Infant hearing. ${ }^{14,15}$ Identification of such indicators in the neonates will help us to keep following up of high-risk babies and to do the necessary investigations as early as possible. Fifty-fold increases in hearing impairment were seen in high-risk infants. ${ }^{17}$ All parents were well convinced, and awareness was created among the parents of infants during the first visit. About $90 \%$ of parents and infants were coming from remote areas. Similar findings were seen in Garg et al. study where more cases seen in rural areas than in urban areas. ${ }^{5}$ The hearing loss in infants without high risk factors was seen as $0.09-2.3 \%,{ }^{17,18}$ and in the high-risk infants, was seen as $0.3-14.1 \%{ }^{19,20}$

According to Maqbool et al. study, 50\% infants may have a hearing impairment without risk factors and noticed when a child misses language milestones. ${ }^{9,16}$ In the present study, $0.9 \%$ of hearing-impaired infants are without any risk factors. It may be due to the tertiary hospital where most of the deliveries are complicated and neonates are with one or more risk factors.

Hearing loss was seen in infants with neonatal asphyxia and craniofacial anomalies. ${ }^{21,22}$

In the present study, $99 \%$ of infants with hearing impairment had risk factors. Hearing loss was seen in three infants $(0.90 \%)$ without any risk factor. In the present study, hearing loss was seen in infants with low birth weight, delayed birth cry, hyperbilirubinemia, and NICU stay.

According to Tanon-Anoh et al., craniofacial anomalies are associated with conductive hearing loss. ${ }^{23}$ According to ColellaSantos, conductive hearing loss was seen in infants with cleft palate, preauricular skin appendages, and ear pits. ${ }^{24}$ Antenatal care may be the reason for no infant had craniofacial malformation.

In Hille et al. study, intubated infants were presented with hearing loss. ${ }^{25}$ According to Bielecki et al., use of ototoxic medication, premature birth, low birth weight, and long admittance in ICU were the risk factors for hearing loss. ${ }^{26}$ According to Maqbool Study, ${ }^{16}$ hearing impairment was seen in $45 \%$ infants with a history of use of ototoxic medications, $30 \%$ infants with hyperbilirubinemia, $26 \%$ infants with perinatal asphyxia, and $10 \%$ of infants with bacterial meningitis.

In the present study, risk factors for the hearing impaired infants were NICU stay (39\%), low birth weight (33.6\%), LSCS (20.6\%), preterm delivery (17\%), hyperbilirubinemia (8.1\%), and delayed cry (7.57\%).

According to Maqbool study, ${ }_{1}^{16}$ none of the study infants had a family history of hearing loss. According to Driscoll et al. study, $1.43 \%$ of infants with a positive family history have hearing loss. ${ }^{27} \mathrm{~A}$ family history of hearing loss is seen along with consanguinity, ${ }^{28-30}$ and the hearing loss in infants depends on the degree of parental consanguinity. ${ }^{28,31}$ In the present study, two infants with a family history of deafness had bilateral PASS, and one infant with a family history of hearing loss had REFER result on OAE. 
The present study had shown similar findings as Hille et al. ${ }^{25}$ and Maqbool study. ${ }^{16}$ According to Vos study, hearing loss was associated with gestational age and birth weight. Intraventricular hemorrhage and congenital white matter lesions in preterm infants are associated with hearing loss. ${ }^{31}$ In the present study, 56 preterm infants had REFER OAE results, and no significant association was seen between gestational age and hearing loss.

Hearing loss was seen in an infant with NICU stay of more than 5 days. ${ }^{32}$ According to Vos study, hearing impairment was seen in $3-14.1 \%$ of babies in $\mathrm{NICU}^{31}$, and $20.68 \%$ of infants with NICU stay of 5 days. ${ }^{31}$ Hearing loss in hospitalized infants may be due to delayed maturation of the auditory system. ${ }^{33}$ According to van Dommelen et al., hearing losses in NICU babies depend on premature birth and birth weight. ${ }^{34}$ Low birth weight was associated with hearing loss. ${ }^{16,34}$ Therefore, whether hearing loss associated with premature birth and low birth weight or NICU stay is controversial. ${ }^{31,35}$ In the present study, 127 infants with NICU stay had REFER OAE results. Hearing loss was seen in $1.2-7.5 \%$ premature babies born in 24-31 weeks. ${ }^{15}$ According to van Dommelen et al., hearing loss was increased in low birth weight babies. About $1.4-4.8 \%$ of babies weighing 750-1500 $\mathrm{g}$ had hearing loss. ${ }^{34}$ In the present study, 111 infants with low birth weight $(<2.5 \mathrm{~kg})$ had REFER OAE results.

Increased bilirubin levels lead to bilirubin-induced neurologic dysfunction (BIND) syndrome. ${ }^{36,37}$ Several studies show that severity of hyperbilirubinemia and duration of hyperbilirubinemia both are associated with hearing loss. ${ }^{36,37}$ Prematurity, sepsis, and hypoxia lead to hyperbilirubinemia. ${ }^{36,37}$ Agrawal et al. had reported hyperbilirubinemia induced BAER abnormalities in infants. ${ }^{38}$ According to Vos, transient hearing disabilities in infants with hyperbilirubinemia can improve after normal bilirubin level. ${ }^{31}$ Auditory damage in infants with hyperbilirubinemia can be prevented by exchange transfusion. ${ }^{39,40}$ In the present study, 27 infants with hyperbilirubinemia had REFER OAE results.

Similar to Güven study, in the present study, hearing loss was not significantly associated with mode of delivery, that is, LSCS and normal delivery.

Through rashtriya bal swasthya karyakram (RBSK), early intervention is provided from birth to 18 years of age. Till the time parents notice the delay in the speech and language, the child had wasted time of 2-3 years of age, which was very important for auditory stimulation. Failure to timely intervene may cause permanent disabilities.

\section{Conclusion}

Statistical analysis performed using the Chi-square test had shown significant association between NICU stay, low birth weight, delayed cry, and hearing loss.

\section{Clinical Significance}

OAE is a good screening tool for newborn and infants.

\section{Compliance with Ethical Standards}

\section{Ethical Approval}

All procedures performed in studies involving human participants were in accordance with the ethical standards of the institutional ethical committee as per ICMR guidelines and University Protocol by letter No. GMCM/IEC-C/78/2020.

\section{Informed Consent}

Informed consent was obtained from parents.

\section{References}

1. Chari DA, Chan DK. Diagnosis and treatment of congenital sensorineural hearing loss. Curr Otorhinolaryngol Rep 2017;5(4): 251-258. DOI: 10.1007/s40136-017-0163-3.

2. Yoshinaga-Itano C, Sedey A. Language, speech and social emotional development of children who are deaf or hard of hearing: the early years. Volta Rev 2000;100(5):181-211. Available from: https://doi. org/10.1093/deafed/8.1.11.

3. Hayes D. Newborn hearing screening: selected experience in the United States. Scand Audiol 2001;30(2):29-32. DOI: 10.1080/010503901750166583.

4. Yoshinaga-Itano C, Sedey AL, Coulter DK, et al. Language of early-and later-identified children with hearing loss. Pediatrics 1998;102(5):11611171. DOI: 10.1542/peds.102.5.1161. PMID: 9794949.

5. Garg S, Singh R, Khurana D. Infant hearing screening in India: current status and way forward. Int J Prev Med 2015;6:113. DOI: 10.4103/20087802.170027.

6. Molini E, Ricci G, Baroni S, et al. Identifying congenital hearing impairment. Personal experience based on selective hearing screening. Acta Otorhinolaryngol Ital 2004;24(3):109-116. PMID: 15584580.

7. Huang JM, Berlin $\mathrm{Cl}$, Keats JB, et al. The application of distortion product otoacoustic emissions to identify carriers of recessive hereditary deafness. In: Berlin C, editor. Hair cells and hearing aids. San Diego: Singular Publishing Group; 1996. p. 57-72.

8. Reuter G, Bordgen F, Dressler F, et al. Neonatal hearing screening with the Echosensor automated device for otoacoustic emissions: a comparative study. HNO 1998;46(11):932-941. DOI: 10.1007/ s001060050338.

9. Joint Committee on Infant Hearing position statement. ASHA 1991;33:3-6. PMID: 1673605.

10. Mauk GW, White KR, Mortensen LB, et al. The effectiveness of hearing programs based on high-risk characteristic in early intervention of hearing impairment. Ear Hear 1991;12(5):312-319. DOI: 10.1097/00003446-199110000-00003.

11. White $K R$, Maxon AB. Universal screening for infant hearing impairment: simple, beneficial, and presently justified. Int $J$ Pediatric Otorhinolaryngol 1995;32(3):201-211. DOI: 10.1016/01655876(95)01165-8.

12. Sharma $P$, Chhangani NP, Meena KR, et al. Brainstem evoked response audiometry (BAER) in infants with hyperbilirubinemia. Indian J Pediatr 2006;73(5):413-416. DOI: 10.1007/BF02758564.

13. Abdullah A, Hazim MYS, Almyzan A, et al. Newborn hearing screening: experience in a Malaysian hospital. Singapore Med J 2006;47(1): 60-64. PMID: 16397723.

14. Joint Committee on Infant Hearing Joint committee on infant hearing position statement. Pediatrics 1995;95(1):152-156. PMID: 7770297.

15. Joint Committee on Infant Hearing, American Academy of Audiology, American Academy of Pediatrics, American Speech-LanguageHearing Association, Directors of Speech and Hearing Programs in State Health and Welfare Agencies. Position statement: principles and guidelines for early hearing detection and intervention program. Pediatrics 2000;106(4):798-817. PMID: 11015525.

16. Maqbool M, Najar BA, Gattoo I, et al. Screening for hearing impairment in high risk neonates: a hospital based study. J Clin Diagn Res 2015;9(6):SC18-SC21. DOI: 10.7860/JCDR/2015/14509.6104.

17. Prieve BA, Stevens F. The New York State universal newborn hearing screening demonstration project: introduction and overview. Ear Hear 2000;21(2):85-91. DOI: 10.1097/00003446-200004000-00003. PMID: 10777016.

18. Korres S, Nikolopoulos T, Komkotou V, et al. Newborn hearing screening: effectiveness, importance of high-risk factors, and characteristics of infants in the neonatal intensive care unit and wellbaby nursery. Otol Neurotol 2005;26(6):1186-1190. DOI: 10.1097/01. mao.0000184602.94677.41.

19. Roth AD, Hildesheimer M, Maayan-Metzger A, et al. Low prevalence of hearing impairment among very low birth weight infants as detected by universal neonatal hearing screening. Arch Dis Child Fetal Neonatal 2006;91(4):257-262. DOI: 10.1136/adc.2005.074476. 
20. Sassada M, Ceccon ME, Navarro J, et al. Avaliacao auditiva de recemnascidos gravemente enfermos atraves do metodo de Emissoes Otoacusticas Evocadas Transientes (EOAT) e audiometria de tronco cerebral (BERA). Pediatria (Sao Paulo) 2005;27(3):154-162. Available from: https://www.ncbi.nlm.nih.gov/pmc/articles/PMC4899359/\#.

21. Shulman S, Besculides $M$, Saltzman A, et al. Evaluation of the universal newborn hearing screening and intervention program. Pediatrics 2010;126(1):S19-S27. DOI: 10.1542/peds.2010-0354F.

22. Coenraad S, Goedegebure A, Hoeve LJ. An initial overestimation of sensorineural hearing loss in NICU infants after failure on neonatal hearing screening. Int J Pediatr Otorhinolaryngol 2011;75(2):159-162. DOI: 10.1016/j.ijporl.2010.10.026.

23. Tanon-Anoh MJ, Sanogo-Gone D, Kouassi KB. Newborn hearing screening in a developing country: results of a pilot study in Abidjan, Cote d'ivoire. Int J Pediatr Otorhinolaryngol 2010;74(2):188-191. DOI: 10.1016/j.ijporl.2009.11.008.

24. Colella-Santos MF, Hein TA, de Souza GL, et al. Newborn hearing screening and early diagnostic in the NICU. Biomed Res Int 2014;2014:845308. DOI: $10.1155 / 2014 / 845308$.

25. Hille ET, van Straaten HI, Verkerk PH, Dutch, NICU Neonatal Hearing Screening Working Group. Prevalence and independent risk factors for hearing loss in NICU infants. Acta Paediatr 2007;96(8):1155-1158. DOI: 10.1111/j.1651-2227.2007.00398.x.

26. Bielecki I, Horbulewicz A, Wolan T. Risk factors associated with hearing loss in infants: an analysis of 5282 referred neonates. Int J Pediatr Otorhinolaryngol 2011;75(7):925-930. DOI: 10.1016/j. ijporl.2011.04.007. PMID: 21571377.

27. Driscoll C, Beswick R, Doherty E, et al. The validity of family history as a risk factor in pediatric hearing loss. Int J Pediatr Otorhinolaryngol 2015;79(5):654-659. DOI: 10.1016/j.ijporl.2015.02.007. PMID: 25758197.

28. Bener A, Eihakeem AA, Abdulhadi K. Is there any association between consanguinity and hearing loss. Int J Pediatr Otorhinolaryngol 2005;69(3):327-333. DOI: 10.1016/j.ijporl.2004.10.004. PMID: 15733591.

29. Feinmesser $M$, Tell L, Levi $H$. Consanguinity among parents of hearing impaired infants in relation to ethnic groups in the Jewish population of Jerusalem. Audiology 1989;28(5):268-271. DOI: 10.3109/00206098909081633.

30. Zakzouk SM, Bafaqeeh SA. Prevalence of severe to profound sensorineural hearing loss in infants having family members with hearing impairment. Ann Otol Rhinol Laryngol 1996;105(11):882-886. DOI: $10.1177 / 000348949610501108$

31. Vos B, Senterre C, Lagasse R, et al. Newborn hearing screening programme in Belgium: a consensus recommendation on risk factors. BMC Pediatr 2015;15:160. DOI: 10.1186/s12887-015-0479-4.

32. Joint Committee on Infant Hearing Year 2007 position statement: principles and guidelines for early hearing detection and intervention programs. Pediatrics 2007;120(4):898-921. DOI: 10.1542/peds. 2007-2333.

33. Koenighofer M, Parzefall T, Ramsebner R, et al. Delayed auditory pathway maturation and prematurity. Wien Klin Wochenschr 2015;127(11-12):440-444. DOI: 10.1007/s00508-014-0653-y. PMID: 25409950.

34. van Dommelen P, Verkerk PH, van Straaten HL. Dutch Neonatal Intensive Care Unit Neonatal Hearing Screening Working Group. Hearing loss by week of gestation and birth weight in very preterm neonates. J Pediatr 2015;166(4):840-843.e1. DOI: 10.1016/j. jpeds.2014.12.041. PMID: 25661409.

35. van Dommelen $\mathrm{P}$, Mohangoo AD, Verkerk PH, et al. Risk indicators for hearing loss in infants treated in different neonatal intensive care units. Acta Paediatr 2010;99(3):344-349. DOI: 10.1111/j.16512227.2009.01614.x.

36. Morioka I, Iwatani S, Koda T, et al. Disorders of bilirubin binding to albumin and bilirubin-induced neurologic dysfunction. Semin Fetal Neonatal Med 2015;20(1):31-36. DOI: 10.1016/j.siny.2014.11.001. PMID: 25432488.

37. Olds C, Oghalai JS. Audiologic impairment associated with bilirubin-induced neurologic damage. Semin Fetal Neonatal Med 2015;20(1):42-46. DOI: 10.1016/j.siny.2014.12.006.

38. Agrawal VK, Shukla R, Misra PK, et al. Brainstem auditory evoked response in newborns with hyperbilirubinemia. Indian Paediatrics 1998;35(6):513-518. PMID: 10216645.

39. Zamani A, Daneshju K, Ameni A, et al. Estimating the incidence of neonatal hearing loss in high risk neonates. Acta Med Iran 2004;42(3):176-180. Available from: https://acta.tums.ac.ir/index. php/acta/article/view/2715.

40. Güven SG. The effect of mode of delivery on newborn hearing screening results. Turk Arch Otorhinolaryngol 2019;57(1):19-23. DOI: 10.5152/tao.2019.3940. 